\title{
SIALODEKTOMI DAN PENGANGKATAN KELENJAR SALIVA SUBMANDIBULA KIRI PADA SIALOLITIASIS (Laporan Kasus)
}

\author{
Ika Ratna Maulani \\ Departemen Bedah Mulut FKG UPDM(B) Jakarta
}

\begin{abstract}
ABSTRAK
Sialolitiasis merupakan peradangan akibat adanya sialolit. Sialolit (batu kelenjar saliva) terjadi oleh karena akumulasi deposit kalsium atau kalkulus yang terbentuk pada duktus kelenjar saliva atau di dalam kelenjar saliva sehingga menghambat aliran kelenjar saliva. Penatalaksanaan sialolitiasis tergantung pada durasi gejala, jumlah timbulnya gejala yang berulang, ukuran batu dan lokasi batu dan kelenjar yang terlibat. Dilaporkan seorang laki-laki berusia 34 tahun datang ke poli Bedah Mulut dan Maksilofasial Rumah Sakit Hasan Sadikin dengan keluhan rasa sakit dan bengkak yang hilang timbul di bagian dalam mulut sebelah kiri bawah sejak 4 tahun sebelumnya. Pasien didiagnosis dengan sialolitiasis disertai ruptur muara kelenjar ludah submandibula kiri regio posterior (distal gigi molar kedua), kemudian dilakukan sialodektomi submandibula kiri dan pengangkatan kelenjar submandibula kiri dengan anestesi umum oleh Bagian Bedah Mulut Rumah Sakit Hasan Sadikin.
\end{abstract}

Kata kunci: sialolitiasis, sialodektomi.

\section{ABSTRACT}

Sialolithiasis is an inflammation condition associated with stone in salivary gland. Sialolith (stone in salivary glands) occur because of the accumulation of calcium or calculus deposits that is formed in the salivary gland ducts or in the salivary glands thereby inhibiting salivary gland flow. Management of sialolithiasis depends on the duration of the symptoms, the number of recurrent symptoms, the size of the stone and the location of the stone and glands involved. Reported by a 34-year-old man came to the Surgery of Mouth and Maksilofasial at Hasan Sadikin Hospital with complaints of pain and swelling that disappeared and arised on the inside of the lower left mouth since 4 years earlier. Patients were diagnosed with sialolithiasis with ruptured salivary glands of the left submandibular gland of the posterior region (distal second molar tooth), who underwent a left submandibular sialodectomy and removal of the left submandibular gland under general anesthesia by the Hasan Sadikin Mouth Surgery Department.

Key words: sialolithiasis, sialodectomy

\section{PENDAHULUAN}

ialolit kelenjar saliva terjadi oleh karena akumulasi deposit kalsium atau kalkulus yang terbentuk pada duktus kelenjar saliva atau di dalam kelenjar saliva sehingga menghambat aliran kelenjar saliva. Etiologi dan patogenesis terjadinya sialolit belum diketahui secara pasti. Namun diduga merupakan serangkaian proses yang diawali dengan abnormalitas metabolisme kalsium dan presipitasi garam. Kemudian diikuti dengan pelapisan bahan organik dan anorganik sehingga terjadi sebuah batu. ${ }^{1}$ Terjadinya sialolit dua kali lebih tinggi pada pria, insidensi tertinggi terjadi pada usia 30 - 50 tahun. $^{2}$

Dalam rongga mulut terdapat dua jenis kelenjar saliva yaitu kelenjar saliva mayor dan minor. Kelenjar saliva mayor terdiri dari kelenjar submandibula, sublingual dan kelenjar parotis. Kelenjar saliva minor terdapat pada daerah labial, bukal, palatum, tonsil, retromolar dan lingual, dilapisi oleh membran mukosa mulut berjumlah 800 sampai 1000 kelenjar yang tersebar dalam rongga mulut. ${ }^{3}$

Selain memberikan lubrikasi untak fungsi bicara, saliva juga berperan dalam fungsi pengunyahan. Kelenjar saliva menghasilkan kira-kira 1000-1500 ml saliva per hari, dengan aliran yang tertinggi terjadi sewaktu makan. Kontribusi produksi tiap kelenjar bervariasi yaitu submandibula $70 \%$, parotis $25 \%$, sublingual 3-4\% dan kelenjar minor sisanya. Komposisi elektrolit saliva juga berbeda tiap kelenjar. Kelenjar parotis konsentrasi elektrolitnya lebih tinggi dari kelenjar submandibula, kecuali konsentrasi kalsiumnya yang dua kali lebih tinggi dari parotis. ${ }^{3}$

\section{LAPORAN KASUS}

Dilaporkan seorang laki-laki berusia 34 tahun datang ke poli Bedah Mulut dan Maksilofasial Rumah 
Sakit Hasan Sadikin dengan keluhan rasa sakit dan bengkak yang hilang timbul di bagian dalam mulut sebelah kiri bawah sejak 4 tahun sebelumnya. Pada pemeriksaan fisik umum didapatkan status umum baik, dengan tanda-tanda vital: frekuensi pernapasan 18x/ menit, frekuensi nadi 80x/menit, tekanan darah 120/80 mmHg; Pemeriksaan fisik lokal didapatkan pada intra oral yaitu vestibulum lingual kiri regio posterior molar kedua terdapat sialolit yang sudah terekspos, ukuran 5x3x1 cm berwarna putih kekuningan. Berdasarkan pemeriksaan klinis, riwayat pasien, pengamatan radiologi (panoramik) (gambar 1), sialografi (gambar 2.A dan 2.B), dan CT-Scan (gambar 3.A dan 3.B), ditegakkan diagnosis sialolitiasis disertai ruptur muara kelenjar ludah submandibula kiri yang direncanakan dilakukan sialodektomi dan pengangkatan submandibula kiri dengan anestesi umum yang dilakukan tanggal 25 Juni 2009.

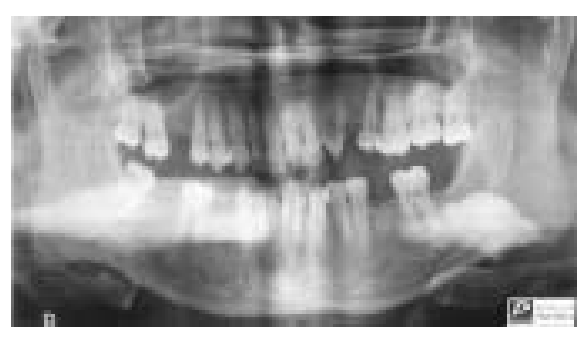

GAMBAR 1.

Foto Panoramik
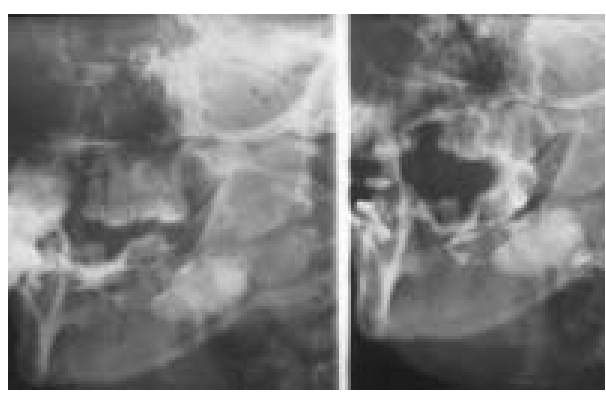

GAMBAR 2.A.

Sialogram, Lateral

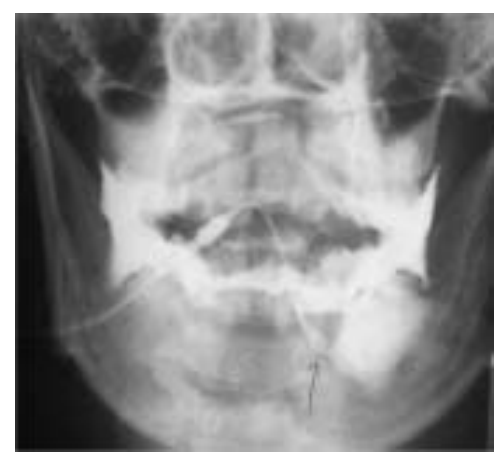

GAMBAR 2.B.

Sialogram AP

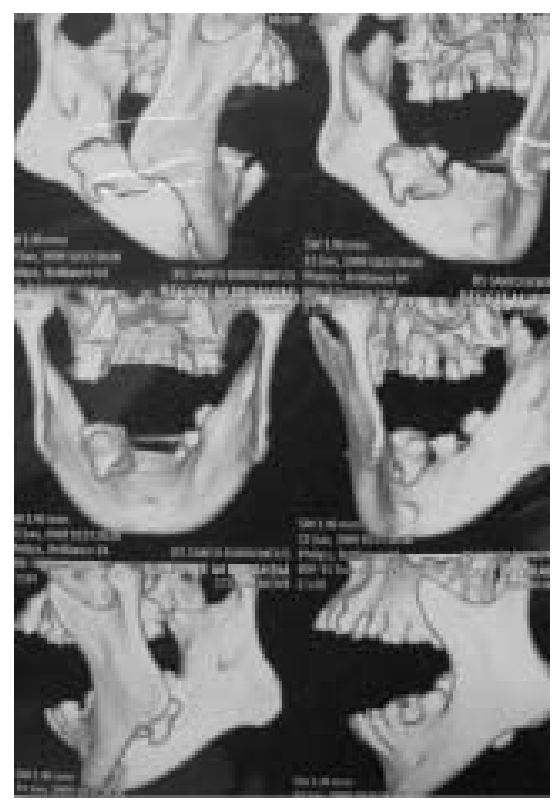

GAMBAR 3.A

CT-Scan 3D
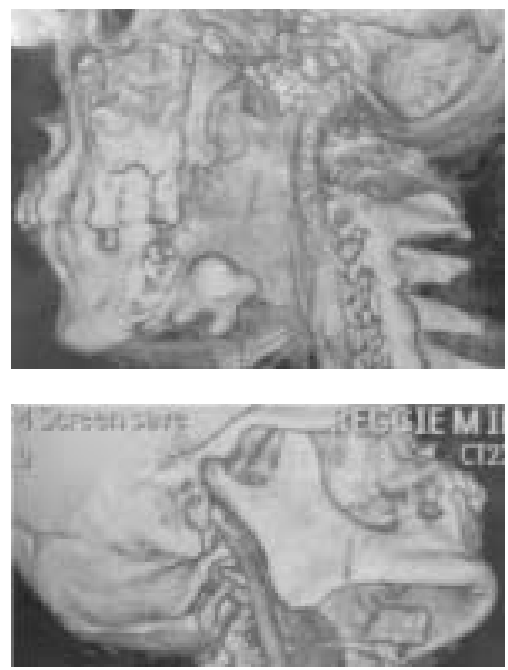

GAMBAR 3.B

CT-Scan 3D, berwarna

Jalannya operasi adalah sebagai berikut; persiapan alat, operator dan asisten, pemasangan infus di tangan kiri, tindakan anestesi umum dengan $\mathrm{O}_{2}$ dan $\mathrm{N}_{2} \mathrm{O}$, injeksi obat-obatan anestesi, tindakan intubasi, pemberian salep mata dan penutupan mata dengan hypafix. Kemudian dilakukan tindakan aseptik ekstra oral; alkohol $70 \%$ dan povidone iodine solution 10\%, intra oral; povidone solution. Lalu dilakukan penutupan tubuh pasien dengan kain steril, kecuali daerah operasi. Untuk mencegah tertariknya selang intubasi selama operasi, dilakukan fiksasi tube nasal dengan benang silk 2.0. Lalu untuk mencegah terjadinya aspirasi, dilakukan pemasangan kassa pack di orofaring.

Selanjutnya, agar didapat lapang pandang operasi yang cukup, dilakukan penjahitan lidah untuk meretraksi lidah ke arah lateral dan pemasangan mouth spreader pada sisi kanan. 


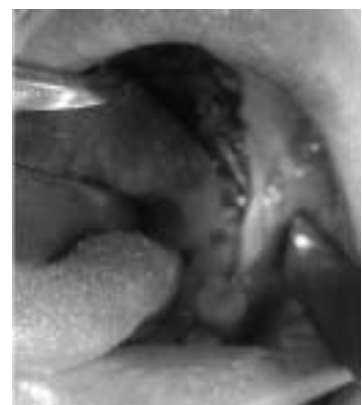

GAMBAR 4.

Intra oral pre op

Operasi dimulai dengan pemberian vasokonstriksi intra oral berupa pemberian adrenalin 1:200.000 pada vestibulum lingual kiri, dilanjutkan dengan insisi pada regio sublingual 3.7-3.8 sinistra untuk memanjangkan jaringan mukosa pada vestibulum yang sudah ruptur dengan blade no. 15. Kemudian dilakukan pemisahan jaringan mukosa dengan rasparatorium dan arteri klem, dilanjutkan dengan pengambilan sialolit serta jaringan granulasi pada rongga bekas sialolit, dan irigasi rongga tersebut dengan larutan $\mathrm{NaCl}$ 0,9\% (gambar 5). Bagian intra oral diakhiri dengan penutupan rongga dengan penjahitan jaringan mukosa pada regio sublingual 3.7-3.8 menggunakan benang vicryl 3.0.
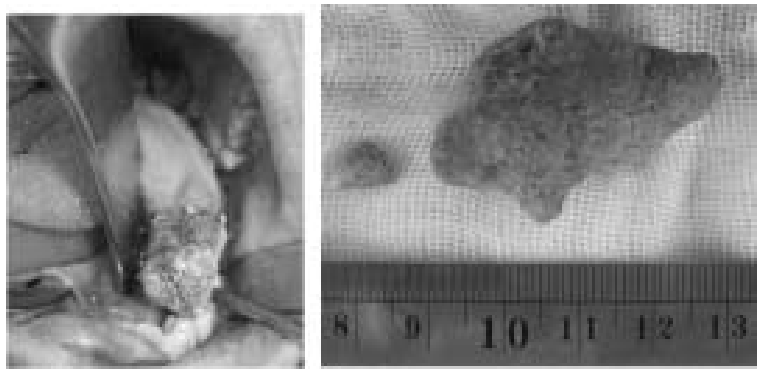

GAMBAR 5.

Sialolit, ditemukan 2, dengan masing-masing berukuran $\pm 1 \times 0,5 \times 0,5 \mathrm{~cm}$ dan $\pm 4 \times 3 \times 1 \mathrm{~cm}$

Selanjutnya dilakukan persiapan untuk pengambilan kelenjar liur submandibula kiri. Pada ekstra oral, dilakukan pembuatan pola regio submandibula kiri 2 jari di bawah tepi mandibula (gambar 6).

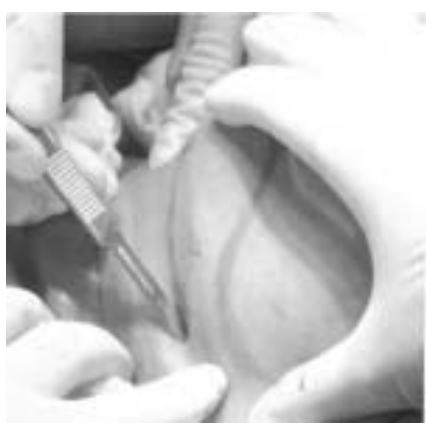

GAMBAR 6.

Pola insisi submandibula kiri
Dilanjutkan dengan insisi kutis pada regio submandibula sinistra dan otot-otot selapis demi selapis sampai terlihat kelenjar liur submandibula kiri dengan blade no.15, cauter, gunting jaringan, arteri klem. Kemudian pemisahan jaringan otot dengan kelenjar liur submandibula kiri dengan menggunakan arteri klem dan kauter. Dilanjutkan dengan pengikatan pembuluh darah dengan benang vicryl 3.0, pemisahan kelenjar liur sublingual dengan submandibula, pengikatan duktus kelenjar submandibula kiri dengan benang vicryl 3.0, pemotongan kelenjar submandibula dari jaringan mukosa dengan kauter, dan pengangkatan kelenjar liur submandibula kiri (gambar 7 dan 8).
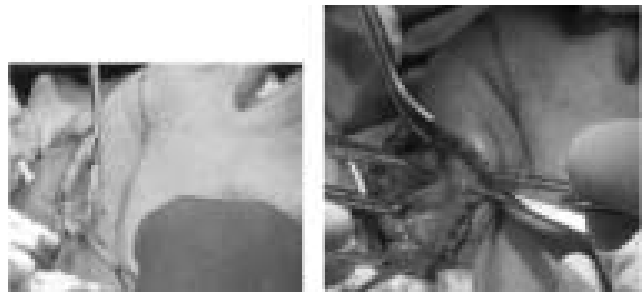

GAMBAR 7.

Pengangkatan kelenjar liur submandibula kiri

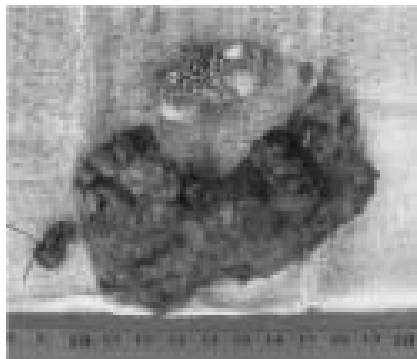

GAMBAR 8.

Ukuran kelenjar liur submandibula kiri $\pm 9 \times 5 \times 2 \mathrm{~cm}$ dan KGB submandibula kiri (benang silk)

Operasi bagian ekstra oral diakhiri dengan irigasi daerah operasi dengan larutan $\mathrm{NaCl} 0,9 \%$, penjahitan otot dengan benang vicryl 3.0, pemasangan penrose drain serta penjahitan subkutis dengan benang vicryl 4.0 dan kutis dengan benang dermalon 4.0 (gambar 9).
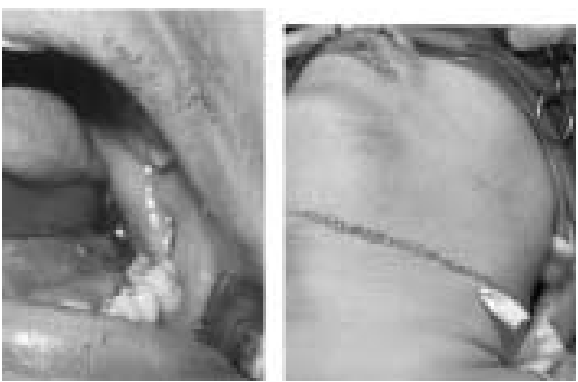

GAMBAR 9.

Intra oral dan ekstra oral post op 
Kemudian bagian intra oral diirigasi dengan larutan $\mathrm{NaCl}$ 0,9\%, diikuti pelepasan kassa pack dari orofaring, pelepasan mouth spreader, pembersihan daerah operasi, pemasangan sufratul dan hipafiks, tindakan ekstubasi dan pengiriman hasil ke patologi anatomi (kelenjar liur submandibula kiri dan kelenjar getah bening submandibula kiri).

Selanjutnya pasien dikontrol setiap hari selama dirawat, kemudian pulang pada hari ke 4 setelah operasi. Pasien kontrol kembali ke poli Bedah Mulut pada hari ke 6, 8, dan 15 setelah operasi. Pada kontrol hari ke 8 dan 15, pasien mengeluhkan adanya parestesi lidah sebelah kiri, sedangkan gerakan lidah normal. Untuk mengatasi keluhan ini, pasien diberikan Neurobion tablet 2 x 1 . Pasien dianjurkan untuk kontrol kembali bila masih ada keluhan, namun sampai laporan dibuat, pasien tidak datang kontrol kembali.

\section{PEMBAHASAN}

Sialolit adalah suatu istilah yang menerangkan adanya batu / struktur kalsifikasi yang berkembang pada kelenjar saliva atau pada duktusnya. Penyebab yang tepat dari sialolit ini belum diketahui secara pasti. Tetapi diduga berasal dari deposisi / endapan garam kalsium sekeliling nodus debris dalam lumen duktus, debris disini termasuk penebalan / pemadatan mukus, bakteri, sel-sel epitel duktus atau benda asing. Stasis yang intermiten dapat merubah elemen mukoid pada saliva menjadi bentuk gel, sehingga gel tersebut merupakan penyusun deposisi garam dan bahan organik menjadi batu. ${ }^{2,4}$ Insidensi terjadinya sialolit sebesar $80 \%$ pada kelenjar submandibula, $19 \%$ pada kelenjar parotis dan $1 \%$ pada kelenjar sublingual. Hal ini disebabkan pada kelenjar submandibula, konsentrasi ion kalsum dan phosphate lebih tinggi daripada kelenjar parotis dan kelenjar sublingual, selain itu duktus ini memiliki dua buah lekukan tajam. Lekukan pertama terletak pada tepi posterior otot mylohyoid dan lekukan kedua terletak dekat muara duktus pada bagian anterior dasar mulut. Batu yang telah dikeluarkan dari saluran kelenjar ludah biasanya berbentuk bulat atau oval, kasar atau halus dan berwarna kekuningan. ${ }^{4}$

Manifestasi klinis adanya batu pada kelenjar ludah timbul pada saat obstruksi duktus yang akut, yaitu pada waktu makan. Pada saat itu produksi saliva berada dalam keadaan maksimum dan aliran saliva terstimulasi. Pembengkakan yang timbul tiba-tiba dan cepat dalam beberapa menit dan terdapat rasa sakit hebat pada saat mulai makan. (gambar 10.A) Kemudian diikuti penurunan pembengkakan secara bertahap sekitar satu jam setelah selesai makan dan pembengkakan muncul kembali ketika aliran saliva terstimulasi kembali. ${ }^{3}$ Gejala tersebut di atas terjadi bila batu menyumbat saluran kelenjar submandibula secara lengkap. Seringkali batu hanya menyebabkan obstruksi sebagian pada bagian hilum kelenjar atau di tengah duktus pada dasar mulut. Pada kasus demikian pembengkakan hanya terjadi sewaktuwaktu disertai rasa tidak nyaman yang minimal atau pembengkakan kronis pada daerah segitiga submandibula dengan rasa sakit yang tumpul. Namun sering juga tanpa disertai gejala dan ditemukan secara kebetulan dan pada pemeriksaan foto radiologis. ${ }^{5}$ Proses gejala ini dapat terjadi terus-menerus sampai pada akhirnya terjadi obstruksi yang lengkap, infeksi ataupun kedua-duanya. Obstruksi tanpa infeksi terjadi karena adanya atrofi sel sekretori kelenjar ludah yang terlibat. Infeksi kelenjar ludah dapat terjadi dengan manifestasi berupa pembengkakan pada dasar mulut, eritema dan limfadenopati. Palpasi pada kelenjar dan pemeriksaan pada duktus dan muaranya dapat terlihat tidak adanya aliran saliva dan adanya pus. ${ }^{3}$ Pada pasien ini gejala klinis telah dirasakan pasien selama 4 tahun namun tidak diperhatikan secara detail. Dari pemeriksaan klinis dan penunjang diketahui sialolit terjadi pada kelenjar submandibular kiri yang sudah membuat muara kelenjar submandibular ruptur.

Bila batu kelenjar diduga terletak pada kelenjar parotis, inspeksi dan palpasi dilakukan sepanjang ramus ascenden mandibula dan dilakukan pemeriksaan intraoral terhadap duktus Stensen dan orifisnya. Observasi dilakukan terhadap aliran saliva dan produksinya seperti adanya pus pada lubang muara duktus. Gejala yang ditemukan antara lain pembengkakan unilateral pada sudut mandibula dan rasa sakit daerah telinga terutama pada saat makan, (gambar 10.B) batu kelenjar parotis yang terdapat pada sepertiga distal duktus Stensen dapat dipalpasi secara intraoral.

Pemeriksaan terhadap adanya batu kelenjar sublingual dapat dilakukan dengan observasi dan palpasi bimanual pada sepertiga anterior dasar mulut. Demikian juga dengan batu kelenjar ludah minor, palpasi dilakukan pada permukaan mukosa bibir, bukal, palatal dan dasar mulut. (gambar 10.C) Obstruksi kelenjar sublingual merupakan kasus yang jarang atau biasanya merupakan obstruksi sekunder dari duktus Wharton pada sisi yang sama di dalam rongga mulut. ${ }^{3}$

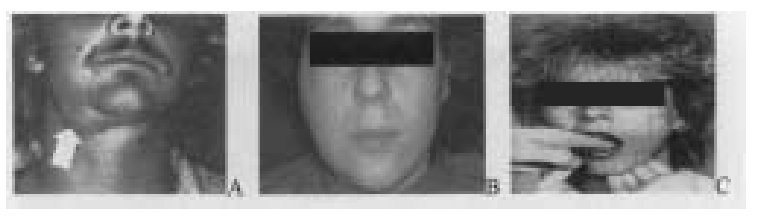

GAMBAR 10.

Manifestasi klinis batu dalam kelenjar ludah

Diagnosis pada kasus ini dilakukan sesuai teori yaitu ditegakkan dengan pemeriksaan klinis yaitu palpasi ekstra oral pada kelenjar ludah palpasi bimanual pada duktus serta observasi kuantitas dan konsistensi aliran ludah. Konfirmasi diagnosis dapat dilakukan pemeriksaan penunjang seperti foto polos X-ray, ultrasonografi, sialografi atau sialoendoskopi dan CTScan (gambar 11). Batu kelenjar ludah submandibular kebanyakan radioopak dan mudah diidentifikasi dengan foto polos panoramik dan oklusal foto. Namun terdapat 
pula batu kelenjar yang radiolusen sehingga tidak dapat dideteksi oleh foto polos radiografik. Sialografi dibutuhkan untuk mendeteksi batu kelenjar jenis ini. Namun prosedur diagnostik ini memiliki resiko terdorongnya batu lebih ke proksimal dari duktus sehingga menyulitkan dalam pengambilannya.
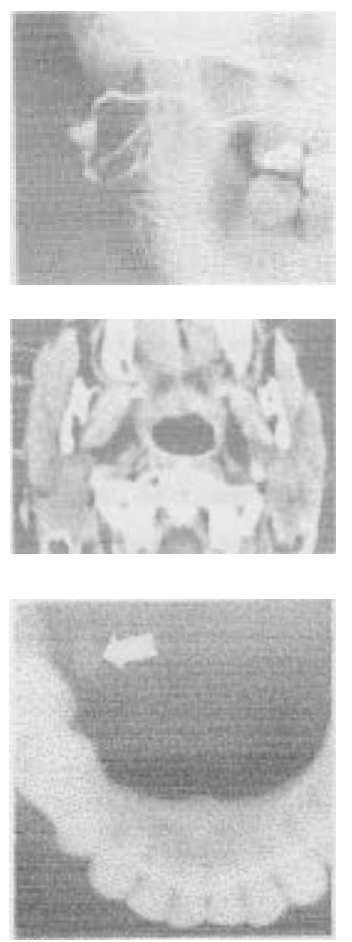

GAMBAR 11.

Pemeriksaan penunjang batu dalam kelenjar liur

Penatalaksanaan batu kelenjar ludah tergantung pada durasi gejala, jumlah timbulnya gejala yang berulang, ukuran batu dan lokasi batu dan kelenjar yang terlibat. Batu kelenjar submandibula dapat diklasifikasikan berdasarkan lokasinya, yaitu di sebelah anterior dan posterior terhadap garis transversal antara gigi molar pertama Batu yang terletak di anterior mudah tervisualisasikan dengan menggunakan foto oklusal dan dapat dicoba dikeluarkan tanpa pembedahan seperti antara lain dengan mendilatasi duktus Wharton dengan probe lakrimalis. Tindakan ini dilakukan dengan hatihati agar tidak mendorong batu lebih ke posterior, kemudian kelenjar dipijat agar saliva lebih banyak keluar atau dengan memberikan stimulus saliva seperti asam sitrus, permen dengan berbagai rasa atau dengan glycerin.

Apabila usaha konvensional tidak berhasil dapat dilakukan insisi pada dasar mulut sehingga duktus terbuka dan batu dapat dikeluarkan dengan mudah. Ikatkan batu di bagian proksimal dengan penjahitan agar batu tidak lari kearah posterior selama pembedahan. Insisi dibuat longitudinal sepanjang mukosa duktus dengan pisau no 15, diseksi tumpul sampai duktus teridentifikasi, fiksasi dengan loop suture untuk memudahkan ekplorasi duktus. Setelah batu terlihat batu dapat dikeluarkan dengan mudah. Dinding duktus dijahitkan pada mukosa dasar mulut untuk mempertahankan drainase saliva dengan Dexon 4-0. Mukosa diatasnya dijahit dengan Dexon 3-0 atau Vicryl. Tindakan ini disebut sebagai sialodochoplasty (reparasi duktus saliva). ${ }^{3}$ Untuk mencegah stenosis akibat terbentuknya jaringan parut, tube karet ukuran kecil dapat diinsersikan pada orifis yang baru selama 8 hari (gambar 12).

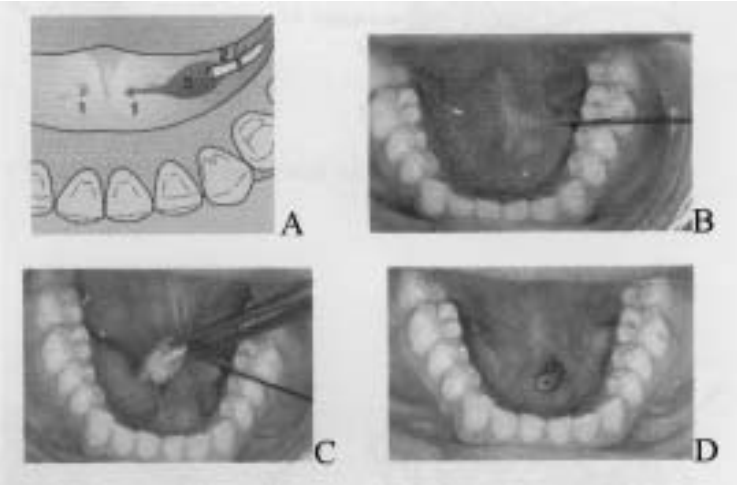

GAMBAR 12.

Apabila batu kelenjar ludah submandibula terletak di posterior atau terletak pada hilum kelenjar atau di dalam kelenjar submandibula itu sendiri maka dapat dilakukan pengangkatan kelenjar submandibula beserta batu di dalamnya dengan pendekatan ekstraoral, yaitu dengan membuat insisi kurang lebih 2 jari di bawah tepi mandibula dengan memisahkan dan meligasi anterior vena fasialis (gambar 13), sementara itu flap superior diangkat untuk menjaga syaraf marginal mandibula. ${ }^{3}$ Sesuai dengan teori ini, kasus pada pasien ini dilakukan pengangkatan sialolit dan kelenjar submandibular kiri.
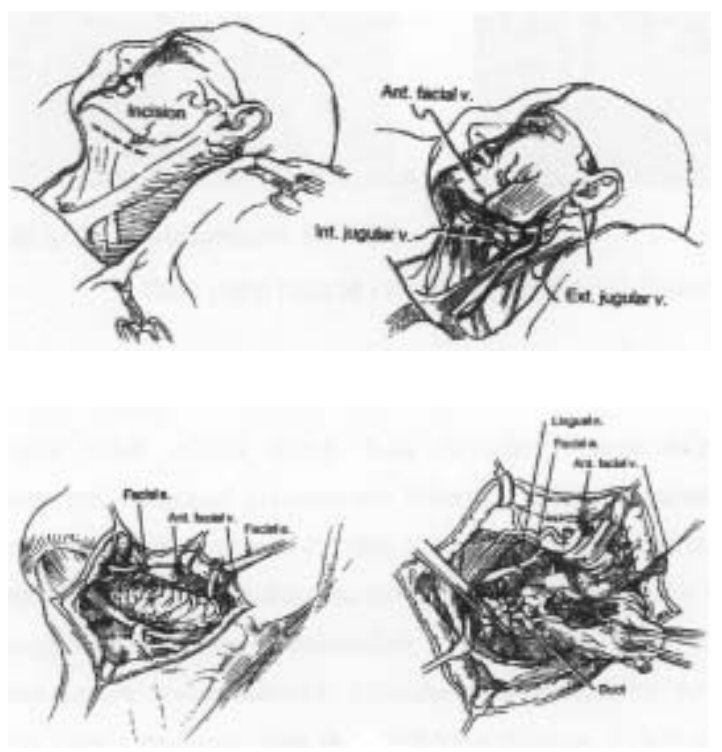

GAMBAR 13 dan 14.

Ligasi dan Deseksi 
Kelenjar dideseksi ke arah superior inferior dan posterior untuk membebaskan dengan struktur jaringan sekitarnya termasuk arteri fasialis superior dan inferior. Syaraf lingual diidentifikasi pada daerah bawah kelenjar kemudian preservasi, syaraf hypoglossal harus dihindari dari trauma pengambilan kelenjar (gambar 14). Penrose drain dipasang sebagai drainase setelah itu dilakukan penjahitan dan dilakukan penekanan dengan verban.

\section{KESIMPULAN}

Kasus sialolitiasis pada pasien ini didiagnosis berdasarkan gejala klinis dan pemeriksaan penunjang yang mendukung. Pemilihan terapi bedah, yaitu sialodektomi dan pengangkatan kelenjar saliva submandibula kiri berdasarkan dengan pertimbangan letak sialolit yang berada pada posterior (distal gigi molar kedua).

\section{DAFTAR PUSTAKA}

1. Graney et.all, 1993, Anatomy and Infection Salivary glands in : Cummings, W.0 et.all, Otolaryngology-Head and Neck Surgery, ${ }_{2}$ nd ed. St Lous Mosby

2. Neville B W, 2004, Oral and Maxillofacial Pathology, WB Saunders Co

3. Miloro M, 2003, Diagnosis and Management of Salivary Gland Disorders in Peterson, Contemporary Oral and Maxillo/acial Surgery, $4^{\text {th }}$ ed, Mosby

4. Siddiqui, S.J, 2002, Sialolithiasis : an unusually large submandibular salivary stone, British Dental Journal July. Vol 193. No 2 www.bu.edu/pactab/litho/ ntro.htint Global Lithotripsy Services How does Lithotripsy Work Accesed April 2006

5. Pedlar J, 2001, Oral and Maxillofacial Surgery, Edinbw'gl , Churchill Livingstones 